Viso - Cadernos de estética aplicada Revista eletrônica de estética

ISSN 1981-4062

No 24, jan-jun/2019

http://www.revistaviso.com.br/
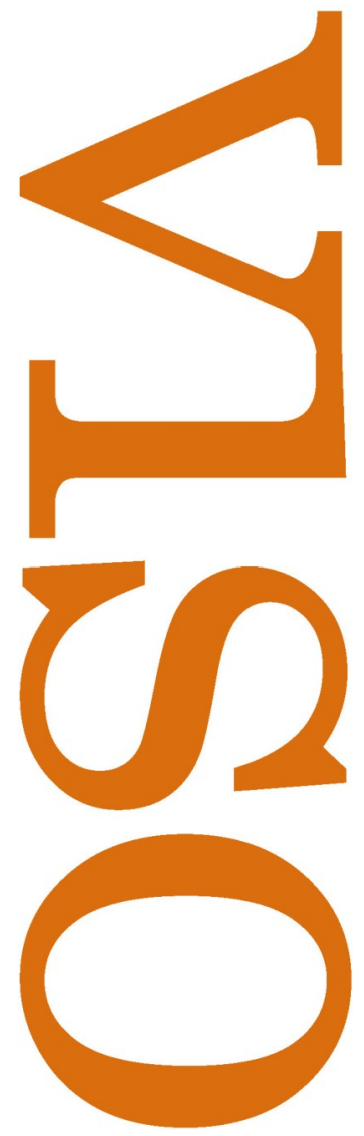

\title{
Deixa o velho Platão franzir seu olho austero ou Queerificando Baudelaire
}

Alexia Bretas

Universidade Federal do $A B C$ (UFABC) 


\section{RESUMO}

\section{Deixa o velho Platão franzir seu olho austero ou Queerificando Baudelaire}

As flores do mal (1857) correspondem ao monumento, por excelência, do ambivalente gênio baudelairiano. Escritos ao longo de vinte e sete anos, os 166 poemas reunidos nesta compilação antológica expressam, segundo Benjamin, o canto de cisne do último grande lírico no auge do capitalismo. Confirmando sua irredutível extemporaneidade, seis de suas "flores doentias" foram sumariamente censuradas pelo tribunal correcional de Paris, sob a alegação de atentar contra a moral e os bons costumes. A posteriori, foram incorporadas ao livro, sob a rubrica "Poemas condenados", na seção "Marginália", na qual "Lesbos" e "Mulheres Malditas" figuram em posição de destaque - de certo modo, justificando o outro título cogitado para As flores do mal: "As Lésbicas". Em todo caso, postado na encruzilhada maldita entre o spleen e o Ideal, a natureza e a história, Baudelaire dá voz aos avatares apócrifos de uma modernidade decadente redimida pela sensibilidade de uma antiguidade heroica. Não por acaso, algumas de suas mais eloquentes invocações performativas encarnam-se em corpos femininos não-normativos, voluptuosamente animados pelo páthos da negatividade: os das lesbianas. Personagens como Safo, Delfina e Hipólita, por exemplo, vêm a protagonizar um enquadramento teórico essencialmente antiplatônico, no qual as múltiplas figuras do antinatural, do anormal e do abjeto são revistas e transvaloradas à luz de uma perspectiva que talvez pudéssemos chamar de "queer" avant la lettre. Trata-se, aqui, de submeter as sublimes composições baudelairianas ao crivo de uma certa genealogia do gênero informada por autoras contemporâneas como Monique Wittig, Judith Butler e Paul Beatriz Preciado.

Palavras-chave: Baudelaire - Flores do mal - mulheres malditas - lésbicas homossexualidade - queer 


\section{ABSTRACT}

\section{Let the Severe Eyes of Old Plato Frown, or Queering Baudelaire}

The Flowers of Evil (1857) are the monument, par excellence, of the ambivalent Baudelairean genius. Written over twenty-seven years, the 166 poems collected in this anthological compilation express, according to Benjamin, the swan song of the last great lyric at the era of high capitalism. Confirming his irreducible extemporaneity, six of his "sick flowers" were summarily censored by the Paris Correctional Court, on the grounds that it was against moral principles. A posteriori, were incorporated into the book, under "condemned Poems" in the "Marginalia" section, where "Lesbos" and "Damned Women" appear in a prominent position - in a way, justifying the other title considered for The Flowers of Evil: "The Lesbians". In any case, posted on the damned crossroads between the spleen and the Ideal, nature and history, Baudelaire gives voice to the apocryphal avatars of a decadent modernity redeemed by the sensitivity of a heroic antiquity. Not by chance, some of his most eloquent invocations are embodied in non-normative female bodies, voluptuously animated by the pathos of negativity: that of lesbians. Characters like Sappho, Delfina and Hippolyta, for example, appear in an essentially anti-Platonic theoretical framework in which multiple figures of the unnatural, of the abnormal and of the abject are reviewed and transvalued in the light of a perspective that we might call "queer" avant la lettre. In order to do so, the sublime Baudelairean compositions will be reframed and illuminated by a certain genealogy of the genre informed by contemporary authors like Monique Wittig, Judith Butler and Paul Beatriz Preciado.

Keywords: Baudelaire - Flowers of Evil - damned women - lesbian - homosexuality queer 


\section{BRETAS, A. "Deixa o velho Platão franzir seu olho austero ou Queerificando Baudelaire". In: Viso: Cadernos de estética aplicada, v. XII, n. 24 (jan-jun/2019), pp. 48-65.}

DOI: $10.22409 / 1981-4062 / v 24 i / 311$

Aprovado: 14.01.2019. Publicado: 30.06.2019.

(C) 2019 Aléxia Bretas. Esse documento é distribuído nos termos da licença Creative Commons Atribuição-NãoComercial 4.0 Internacional (CC-BY-NC), que permite, exceto para fins comerciais, copiar e redistribuir o material em qualquer formato ou meio, bem como remixá-lo, transformá-lo ou criar a partir dele, desde que seja dado o devido crédito e indicada a licença sob a qual ele foi originalmente publicado.

Licença: http://creativecommons.org/licenses/by-nc/4.0/deed.pt_BR

Accepted: 14.01.2019. Published: 30.06.2019.

(C) 2019 Aléxia Bretas. This document is distributed under the terms of a Creative Commons Attribution-NonCommercial 4.0 International license (CC-BY-NC) which allows, except for commercial purposes, to copy and redistribute the material in any medium or format and to remix, transform, and build upon the material, provided the original work is properly cited and states its license.

License: http://creativecommons.org/licenses/by-nc/4.0/ 
Laisse du vieux Platon se froncer l'oeil austère;

Tu tires ton pardon de l'excès des baisers,

Reine du doux empire, aimable et noble terre,

Et des raffinements toujours inépuisés.

Laisse du vieux Platon se froncer l'oeil austère.

Charles Baudelaire. "Lesbos", As flores do mal.

Compilada no ensaio O pintor da vida moderna, a estética baudelairiana orbita em torno de três núcleos principais, a saber: a concepção da Modernidade como Antiguidade, o repúdio à natureza como critério normativo e o irredutível caráter destrutivo. A respeito deste último aspecto, Benjamin destaca a função dos "extremos" na construção de uma mediação dialética ainda não inteiramente desenvolvida na obra de Baudelaire marcada por um pathos, a um só tempo, destrutivo e purificador. "Sua ira destrutiva visa particularmente o conceito fetichista de arte. Desta forma, ela serve à arte 'pura' no sentido de uma arte 'purificada'". ${ }^{1}$ Mas do que exatamente Baudelaire buscava purificar a arte de seu tempo? E o que ele pretendia "destruir" com a sua pena? Para responder a estas questões candentes, há que se retomar a intenção do autor ao elaborar uma "teoria racional e histórica do belo, em oposição à teoria do belo único e absoluto" 2 , expressa no famoso ensaio no qual a Modernidade se faz presente, sobretudo, em seus aspectos passageiros, fugidios e contingentes - via de regra, excluídos das representações canônicas cultuadas em museus e galerias. Vale lembrar que, para o crítico e poeta-alegorista, o belo é constituído de um elemento eterno, invariável, e de um elemento relativo, circunstancial - o qual não deveria jamais ser suprimido em nome de uma arte idealizada, privada de um corpo e abduzida da história. Daí a concepção estética proposta por Baudelaire ser essencialmente antiplatônica, pois recusa a submissão compulsória a um único modelo ideal apreendido pelo Espírito, celebrando, em vez disso, a materialidade e as múltiplas metamorfoses do sensível em suas mais diversas figuras, como é o caso do flâneur, do dândi, das mulheres e, em especial, das lésbicas.

\section{A MULHER}

Publicado pela primeira vez em 1863, no jornal parisiense Figaro, o ensaio O pintor da vida moderna destina três de suas treze seções aos encantos e mistérios do "universo feminino" (mundus muliebris) - são elas "A mulher", "Elogio da maquiagem" e "As mulheres e as moças". Localizado entre duas partes dedicadas à caracterização respectivamente do "Dândi" e dos "Carros", o comentário baudelairiano sobre as mulheres, não obstante os elogios, trai um viés irredutivelmente estetizante, sexista e aristocrático - sobretudo, quando confrontado com perspectivas feministas ou mesmo queer, intempestivamente. ${ }^{3}$ Cedendo à tentação de uma certa epistemologia "masculinista" ao fazer - e ainda responder! - a pergunta sobre a "essência" da mulher ou simplesmente sobre "o que" ela é, Baudelaire arrisca uma definição positiva que a apresenta não apenas como "fêmea do homem"4 senão como um ser "fascinante" e 
"enigmático", temido e desejado como fonte primária de beleza, prazer e cobiça - de certo modo, como as botas, os cavalos e a África.

O ser que é, para a maioria dos homens, a mais viva das fontes, e mesmo, digamo-lo, para a vergonha das volúpias filosóficas, dos mais duradouros prazeres; o ser para o qual - ou em benefício do qual - tendem todos os esforços; esse ser terrível e incomunicável como Deus (com a diferença de que o infinito não se comunica porque cegaria e esmagaria o finito, enquanto o ser de que falamos não é incompreensível senão, talvez, porque nada tem a comunicar); esse ser no qual Joseph de Maistre via um belo animal cujas graças alegravam e tornavam mais fácil o jogo sério da política; para o qual e pelo qual se fazem e se desfazem as fortunas; para o qual, mas sobretudo pelo qual os artistas e os poetas compõem suas mais delicadas joias; do qual advêm os mais debilitantes prazeres e as mais fecundas dores; a mulher, numa palavra, não é apenas para o artista em geral, e para o Sr. G., em particular, a fêmea do homem. É antes, uma divindade, um astro, que preside todas as concepções do cérebro masculino; é uma resplandescência de todas as graças da natureza condensadas num único ser; é o objeto da mais viva admiração e curiosidade que a moldura da vida pode oferecer ao espectador. É uma espécie de ídolo, estúpido talvez, mas deslumbrante, fascinante, que mantém os destinos e as vontades pendentes de seus olhares. ${ }^{5}$

Como Benjamin chamará atenção em seu ensaio sobre a Modernidade, a teoria de Baudelaire se constitui pelo acirramento das tensões entre extremos inconciliáveis. Neste sentido, a mulher é, ao mesmo tempo, "terrível" e "incomunicável", "estúpida" e "deslumbrante"; um ser que nunca é referido como propriamente humano, mas, em vez disso, celebrado ora como feral, ora como divino. Em todo caso, sua existência tem o propósito de tornar mais palatável a vida dos homens empenhados no "jogo sério da política" - atividade da qual a mulher é categoricamente excluída, uma vez que the faltam, supostamente, as prerrogativas do entendimento e da linguagem. ${ }^{6}$ Neste particular, as palavras de Baudelaire ressoam as de dois outros grandes senhores da filosofia moderna, Schopenhauer e Nietzsche, cujas ideias refletem o Zeitgeist heteronormativo e misógino que marca o século XIX europeu e seu discurso patologizante sobre a sexualidade. ${ }^{7}$ Assim, enquanto Baudelaire recorre a Joseph de Maistre para olhar a mulher como um "belo animal", Nietzsche reitera uma certa animalidade ou quase-humanidade feminina, dirigindo-se à mulher em termos não menos subalternizantes como a "um animal doméstico bem delicado, curiosamente selvagem e frequentemente agradável". ${ }^{8}$ Congratulando-se que a tarefa do esclarecimento [Aufklärung] tenha permanecido "entre nós", como um "dom" masculino", o filósofo, com Schopenhauer, exorta: "A mulher se cale acerca da mulher!". ${ }^{10}$ Seu polêmico mestre educador, por sinal, já havia caracterizado o sexo feminino de modo semelhante, retratando as mulheres como criaturas proto-humanas - "infantis", "tolas" e com "visão curta" 11 -, deste modo, posicionando-as aquém do homem, em uma espécie de limbo ou "estágio intermediário" entre a criança e o homem adulto. Inimigo mordaz de uma "galanteria francesa fora de moda" responsável pela "veneração despropositada às mulheres" como "a mais fina flor da estupidez germano-cristã"12 incorporada ao Romantismo, o filósofo é taxativo: "as mulheres são o sexus sequior, o sexo que sob qualquer ponto de vista é o inferior, o segundo sexo". ${ }^{13}$ Justificando a potente indignação 
que moverá Simone de Beauvoir a redigir, no século seguinte, seu magnífico libelo contra o tríplice "destino da mulher"14, Schopenhauer chega a ser didático: "as mulheres existem somente para a propagação da espécie, e seu destino se reduz a isso". ${ }^{15}$ De acordo com seus argumentos, o homem possui a vantagem da força e da beleza, o que explicaria o instintivo pendor da mulher para o vitimismo e a submissão. ${ }^{16}$ Quanto aos méritos intelectuais, todo o "sexo fraco" padeceria de uma "mente míope" e de uma "razão débil"; motivo pelo qual mesmo as cabeças mais brilhantes jamais teriam acrescentado às "belas-artes" uma única grande contribuição. ${ }^{17}$ Diante das evidências, 0 metafísico do belo não mede palavras ao qualificar o sexo feminino como "não estético" por definição. E explica: "Nem para a música, nem para a poesia, tampouco para as artes plásticas as mulheres têm, real e verdadeiramente, talento e sensibilidade; quando, porém, elas afetam ou simulam estas qualidades, de nada mais se trata senão de pura macaquice voltada a seu desejo de agradar". ${ }^{18}$

Em compensação, privada de sensibilidade e mesmo de qualquer talento para as artes, a mulher é alçada ao posto suplementar de objeto de culto e/ou eterna musa da viril genialidade masculina. Ao incorporar a fórmula stendhaliana da beleza como "promesse de bonheur" em seu magistral elogio da moda, Baudelaire prossegue a digressão sobre o "belo sexo" comparando-o a um "convite à felicidade", a uma espécie de "harmonia geral" propiciada pela combinação perfeita entre seu corpo e suas vestimentas - a qual faria de ambos, "mulher" e "vestido", uma "totalidade indivisível".

A mulher é, sem dúvida, uma luz, um olhar, um convite à felicidade, às vezes uma palavra; mas ela é, sobretudo, uma harmonia geral, não apenas em seu porte e no movimento de seus membros, mas também nas musselinas, nas gazes, nas enormes e rutilantes nuvens de pano em que se envolve e que são como que os atributos e o pedestal de sua divindade; [...] qual poeta ousaria, na pintura do prazer causado pela aparição de uma bela mulher, separá-la de sua vestimenta? Qual homem, na rua, no teatro, no bosque, não desfrutou, da maneira mais desinteressada, de uma toalete habilmente composta, e não guardou dela uma imagem inseparável da beleza daquela a quem ela pertencia, fazendo, assim, dos dois, mulher e vestido, uma totalidade indivisível? É o momento, parece-me, de voltar a certas questões relativas à moda e aos adereços, apenas sugeridos no começo deste estudo, e de vingar a arte da toalete das calúnias absurdas de que a cobrem certos amantes bastante equívocos da natureza. ${ }^{19}$

\section{A NATUREZA}

Deste modo, no afã de apoiar sua teoria da moda em preceitos "históricos" e "racionais", Baudelaire se arvora contra uma certa "estética das pessoas que não pensam", segundo a qual "a natureza embeleza a beleza" [La nature embellit la beauté]. Para ele, a maioria dos erros relativos ao belo é engendrada por uma determinada concepção de moral que passa a valer como norma a partir do século XVIII - quando a natureza é apropriada como base, fonte e modelo de todo o bem e de todo o belo. $\mathrm{Na}$ contracorrente de 
pensadores românticos como Rousseau e materialistas como Sade, Baudelaire parte da premissa de que "a natureza não ensina nada".

[...] Ela [a natureza] compele o homem a dormir, a beber, a comer e a se proteger, bem ou mal, contra as hostilidades da atmosfera. É ela, igualmente, que leva o homem a matar seu semelhante, a devorá-lo, a sequestrá-lo, a torturá-lo; pois, tão logo saímos da ordem das necessidades e das precisões, para entrar na do luxo e dos prazeres, vemos que a natureza não pode aconselhar senão ao crime. É esta infalível natureza que criou o parricídio e a antropofagia, e mil outras abominações que o pudor e a polidez nos impedem de explicitar. É a filosofia (refiro-me à boa), é a religião que manda que alimentemos parentes pobres e enfermos. A natureza (que nada mais é do que a voz de nosso interesse) nos manda abatê-los. Passem em revista, analisem tudo o que é natural, todas as ações e desejos do puro homem natural: não encontrarão nada que não seja terrível. Tudo o que é belo e nobre é o resultado da razão e do cálculo. $\mathrm{O}$ crime, cujo gosto o animal humano adquiriu no ventre de sua mãe, é de origem natural. A virtude, ao contrário, é artificial, sobrenatural, pois foram necessários, em todos os tempos e em todas as nações, deuses e profetas, para ensiná-la à humanidade animalizada; virtude que o homem, sozinho, fora incapaz de descobrir. O mal faz-se sem esforço, naturalmente, e por fatalidade; o bem é sempre o produto de uma arte. Tudo quanto digo a respeito da natureza, como má conselheira em matéria de moral, e da razão, como verdadeiramente redentora e reformadora, pode ser transposto para a ordem do belo. ${ }^{20}$

Assim, incapaz de orientar seja nossos critérios estéticos, seja nossa conduta moral, a natureza não deve ser nem obedecida nem imitada, senão combatida e mesmo superada através de todos os artifícios à disposição - como a maquiagem, as vestimentas e a toalete. Em nome de uma beleza "mágica" e "sobrenatural", o autor afirma que a moda expressa o "gosto do ideal" que transforma tudo o que a "vida natural" produz de "grosseiro", de "terrestre" e de "imundo". Percebidos como uma espécie de "deformação sublime da natureza", as roupas e demais artifícios com os quais a mulher se enfeita - e se confunde - devem ser promovidos e cultivados como uma tentativa permanentemente renovada de escapar do domínio da Mãe-natureza. Elogiando a aplicação da maquiagem e, em especial, do pó-de-arroz como "truque" apto a eliminar manchas e outras imperfeições naturais, Baudelaire enaltece suas propriedades e benefícios estéticos ao aproximar a figura do ser humano da de uma estátua - isto é, de um ser "divino" e "superior". Afinal, na condição de "astro" ou "ídolo" - cujos encantos pairam acima da natureza - a mulher "deve dourar-se para ser adorada". ${ }^{21}$

Ciente do possível desagrado por parte de estetas e críticos conservadores pouco afeitos ao culto do belo inclusive em suas manifestações mais diminutas, Baudelaire é categórico: "o seu julgamento austero em nada me afeta". ${ }^{22}$ Assim, tomando como pretexto as ilustrações de Constantin Guys, o poeta elabora uma espécie de taxonomia dos mais diversos perfis femininos que habitam e circulam por metrópoles modernas como Londres e Paris - nas quais "as diferenças de casta e de raça" saltam imediatamente aos olhos do observador eurocêntrico. Damas, moças, mulherzinhas, amantes, boêmias, atrizes, cortesãs: seja qual for a categoria e a indumentária, nenhuma delas escapa do zelo meticuloso com o qual Baudelaire designa seu lugar entre as 
demais, empenhando-se em transmutar aquilo que toma como matéria-prima - a "simples mulher" (foemina simplex) - em pedra filosofal - a mulher em si. De acordo com sua perspectiva, o que torna as imagens de Guys tão interessantes é precisamente o fato de desencadearem numerosos pensamentos e reflexões de caráter estético e, sobretudo, moral. "O que constitui a beleza particular dessas imagens é sua fecundidade moral. Elas estão plenas de sugestões, mas de sugestões cruéis, duras, que minha pena, ainda que acostumada a se debater com as representações plásticas, talvez não tenha traduzido senão insuficientemente". ${ }^{23}$ Por isso, quem as contempla de perto, com as lentes baudelairianas, "não encontrará nada além do vício inevitável, isto é, o olhar do demônio emboscado nas trevas, ou as espáduas de Messalina resplandecendo sob a luz do gás; nada além da arte pura, isto é, da beleza particular do mal, da beleza do horrível". ${ }^{24}$

\section{AS LÉSBICAS}

É, portanto, sob os auspícios desta "beleza particular do mal" ou do "horrível" que As flores do mal são redigidas, "com furor e paciência", ao longo de quase trinta anos. Em correspondência ao notário de Neuilly, Baudelaire confidencia: "Neste livro atroz, coloquei todo o meu coração, toda a minha ternura, toda a minha religião (travestida), todo o meu ódio". ${ }^{25} \mathrm{E}$ mais adiante, prognostica: "Les fleurs du mal... se começará talvez a compreendê-las em alguns anos" ${ }^{26}$ Publicadas pela primeira vez em 1857, As flores do mal realizam a profecia baudelairiana, despertando a indignação e a repulsa de seus contemporâneos, tanto no meio artístico, quanto fora dele. "Sinistras" e "frias", suas "fleurs maladives" (flores doentias) florescem à revelia das leis naturais, desafiando a própria noção de normalidade - seja ela biológica, estética ou moral. Não por acaso, seis de seus poemas foram proibidos pelo tribunal correcional da Paris de Napoleão III, vindo a lume apenas em 1866 - mesmo ano em que Courbet escandalizaria a arte de salão com $A$ origem do mundo e $O$ sono - este último representando um casal de mulheres nuas abraçadas sensualmente sobre a mesma cama. Entre os poemas censurados, estavam "Lesbos" e "Mulheres malditas - Delfina e Hipólita" - cuja importância pode ser medida pelo fato de terem inspirado o outro título por muito tempo aventado pelo autor: "As lésbicas".

Corroborando uma certa visibilidade sáfica nos romances franceses do século XIX com A Fragoletta (1829) de Latouche, A menina dos olhos de ouro de Balzac (1835) e Mademoiselle de Maupin (1835) de Gautier, o poema "Mulheres malditas" [Femmes damnées], na seção As flores do mal, exibe uma construção literária propositalmente ambivalente, por meio da qual Baudelaire rende homenagens - poéticas e aporéticas às suas "pobres irmãs" - como ele, condenadas à maldição dos amores escusos nos quais a "espuma do prazer" se funde às "lágrimas do tormento". Virgens e demônios; monstros e mártires; devotas e sátiras, estas mulheres sofredoras e, não obstante, apaixonadas portam em seus corpos as chagas das santas, mas também as cicatrizes 
das pecadoras. Razão de Baudelaire - como seu igual - amá-las e lamentá-las o mesmo tanto.

Ô vierges, ô démons, ô monstres, ô martyres,

De la réalité grands esprits contempteurs,

Chercheuses d'infini, dévotes et satyres,

Tantôt pleines de cris, tantôt pleines de pleurs,

Vous que dans votre enfer mon âme a poursuivies,

Pauvres soeurs, je vous aime autant que je vous plains,

Pour vos mornes douleurs, vos soifs inassouvies,

Et les urnes d'amour dont vos grands coeurs sont pleins ! 27

Neste poema, o conflito entre os opostos não promete o alívio de uma síntese apaziguadora; ao contrário, delimita os pontos extremos de uma constelação saturada de tensões insolúveis. Misto de prazer e dor, pureza e destruição, as lésbicas baudelairianas são os grandes epítomes da negatividade imanente; ao lado de Caim e do próprio Lúcifer, encarnam-se neste crepúsculo romântico como os avatares satânicos da revolta absoluta. Consideradas tão mais "belas" quanto mais marginalmente se situam em relação às normas, são, ao mesmo tempo, ameaças e alvo de uma ordem patriarcal heteronormativa naturalizada como virtuosa.

Este pathos contraditório é bastante pungente em um dos poemas mais eloquentes e não menos melancólicos de todo o livro: "Lesbos". "Mãe dos jogos latinos" e das "volúpias gregas", Lesbos corresponde à heterotopia baudelairiana do século VI a.C. revisitado pelo século XIX - conjunção de tempos, espaços e corpos, onde os beijos "tempestuosos e secretos, fervilhantes e profundos" ornam "as noites e os dias gloriosos". ${ }^{28}$ Cartografia por excelência de um erotismo agridoce ${ }^{29}$, Lesbos é o locus onde vicejam os frutos de uma antinatureza exuberante e infértil; um éden infernal onde "os beijos são como cascatas", incitando as delícias amargas das "volúpias estéreis". Antípoda da Paris do Segundo Império, a ilha que empresta seu nome à própria caracterização da homossexualidade feminina, inicialmente como patologia ${ }^{30}$, é assim transfigurada e redimida por Baudelaire como a "terra das noites quentes e langorosas", onde "as Frinéias se atraem umas às outras" e até Afrodite tem ciúmes de Safo - esta última, "viril", "amante" e "poeta", a erguer-se sobre o mundo "mais bela do que Vênus". Sobre a representação das lésbicas como heroínas da modernidade, Walter Benjamin observa:

A antiguidade de Baudelaire é romana. Só num ponto a antiguidade grega sobressai em seu universo. A Grécia fornece-lhe a imagem da heroína que lhe parecia digna e capaz de ser transferida para a modernidade. Nomes gregos - Delfina e Hipólita - são dados às figuras femininas num dos maiores e mais famosos poemas de As flores do mal, dedicado ao amor lésbico. A lésbica é a heroína da modernidade. Nela um ideal erótico de Baudelaire - a mulher que evoca dureza e virilidade - se combina a um ideal histórico - o da grandeza do mundo antigo. Isso torna inconfundível a posição da mulher lésbica em As flores do mal. ${ }^{31}$ 
Já Olgária Matos, referindo-se a Baudelaire como "o duplo de Safo, vislumbra na figura da lesbiana a própria "negação da fatalidade do corpo" - mobilizado e transvalorado pelo poeta maldito, à la Preciado, como locus de resistência de uma "antiphysis" e, ao mesmo tempo, de uma "contrarreligião".

As lesbianas das Flores do mal são as damnées que romperam o pacto social, ou ainda, o 'pacto natural', entregando-se a práticas amorosas transgressivas, ou pior, a um modo de vida que ignora a partição do masculino e do feminino, recusando o tipo de amor que mutilaria a sexualidade. Safo, a mulher-dândi, é a perfeição da antiphysis e da contrarreligião - ela dramatiza também o desterro do poeta no momento do capitalismo, que Ihe retirará qualquer missão..$^{32}$

Privado de missão transcendente, Baudelaire, no entanto, julga-se escolhido para cantar os hinos e lamentos desta "religião augusta", tendo sido, desde a infância, iniciado nos mistérios desse "doce império".

Que nous veulent les lois du juste et de l'injuste?

Vierges au coeur sublime, honneur de l'archipel,

Votre religion comme une autre est auguste,

Et l'amour se rira de l'enfer et du ciel!

- Que nous veulent les lois du juste et de l'injuste?

Car Lesbos entre tous m'a choisi sur la terre

Pour chanter le secret de ses vierges en fleur,

Et je fus dès l'enfance admis au noir mystère

Des rires effrénés mêlés au sombre pleur;

Car Lesbos entre tous m'a choisi sur la terre. ${ }^{33}$

Ao ressaltar sua irmandade espiritual com a ilha grega, Baudelaire destaca o caráter disruptivo e desestabilizante da sexualidade lésbica, situando esse amor fora dos padrões para além das coordenadas que definem o que é o belo, o que é o justo, o que é verdadeiro. Ao revelar "o segredo destas virgens em flor" como desvio ou inversão do sistema sexo-gênero, o poeta enaltece um modo de vida aberrante, cujos méritos estão em tensionar os discursos normalizadores, sejam eles estéticos, científicos ou jurídicos: "Que Deus ousará, Lesbos, ser seu juiz!". ${ }^{34}$

Já no poema literalmente condenado pelo tribunal de Paris, "Mulheres malditas", é a "soberba" e "despótica" Delfina quem vocaliza provocação semelhante: "Quem diante do amor ousa falar do inferno?". ${ }^{35}$

Maudit soit à jamais le rêveur inutile

Qui voulut le premier, dans sa stupidité,

S'éprenant d'un problème insoluble et stérile,

Aux choses de l'amour mêler l'honnêteté ! 
Celui qui veut unir dans un accord mystique

L'ombre avec la chaleur, la nuit avec le jour,

Ne chauffera jamais son corps paralytique

A ce rouge soleil que l'on nomme l'amour ! 36

Conforme se percebe, o amor baudelairiano é pós-binário. Refratário tanto a um maniqueísmo vulgar, quanto a uma síntese conciliadora, ele fricciona, dialeticamente, suas contradições internas, fazendo lampejar as centelhas do infinito - aqui, corporificado pelo casal lésbico Delfina e Hipólita. Protagonistas de uma Modernidade configurada como inferno, elas trazem em seus próprios nomes os vestígios de uma Antiguidade grega, a um só tempo, ideal e histórica, mítica e heroica. Delfina é uma criatura "monstruosa" - metade mulher, metade serpente - encarregada de proteger o famoso Oráculo de Delfos regido pela máxima do "conhece-te a ti mesmo"; Hipólita, por sua vez, é uma das mais célebres rainhas amazonas, usualmente representada como uma mulher altiva e guerreira, portadora do cobiçado cinturão apropriado por Hércules em seu nono trabalho. Versificado em "Femmes damnées", seu amor apócrifo se consuma, portanto, como um gesto de repúdio contra os códigos médicos, morais e legais naturalizados como expediente de gestão da vida nas sociedades disciplinares. Sua hybris, contudo, não é isenta de castigo e/ou punição. Proscritas da esfera pública sob o pretexto da normalidade, são exiladas, por assim dizer, nas próprias alcovas, onde partilham uma existência fantasmagórica, perfeitamente invisível ao olhar "austero" - e não menos hipócrita - de seus contemporâneos.

Assim, representadas como criaturas orgulhosas e "malditas" condenadas a gozar - mas também a purgar - seus prazeres anômalos dans le boudoir, as lésbicas baudelairianas se posicionam nos umbrais de uma dada concepção de homossexualidade que ganharia corpo com a publicação do clássico de Krafft-Ebing, Psychopathia Sexualis, em 1886. Vale lembrar que seu controvertido estudo "clínico e forense" diagnosticaria, pela primeira vez, o amor lesbicus não como desvio ou perversão moral, senão como doença do sistema nervoso - a paraestesia.

O estudo científico da psicopatologia da vida sexual trata necessariamente das misérias do homem e dos lados escuros de sua existência, cuja sombra contorce a imagem sublime da divindade em caricaturas horríveis e o desvia do esteticismo e da moralidade. É o triste privilégio da medicina, e especialmente o da psiquiatria, testemunhar sempre as fraquezas da natureza humana e do lado reverso da vida. ${ }^{37}$

Segundo Krafft-Ebing, bem como uma extensa lista de autoridades científicas consultadas por ele, as mulheres homossexuais fariam parte de uma pletórica galeria de "psicopatas sexuais" - entre os quais estavam também os fetichistas, os sádicos, os masoquistas, os sodomitas, os pederastas, os necrófilos e os bestialistas -, cabendo aos médicos o dever "sagrado" não apenas de tudo ver, mas também de tudo falar.

Movido por vocação análoga, Baudelaire, no entanto, segue a via estritamente poética ao celebrar seu culto profano aos prazeres "desviantes". Transvalorando e 
ressignificando o estigma da homossexualidade feminina como doença, ele tem o mérito de atribuir-Ihe um caráter insoluvelmente "puro" e "antinatural" - como vimos, fundamental em sua crítica estética. Não obstante, sua postura em relação à lesbianidade não apenas como topos poético, senão também como questão social, revela-se, ao fim e ao cabo, paradoxal. Pois enquanto, em As flores do mal, as lesbianas são esculpidas e iluminadas pela sublime "beleza do horrível", na vida real tudo leva a crer que o crítico sequer as notava - ou se as notava, dirigia-Ihes um tratamento não de cumplicidade ou admiração como na poesia, senão de indiferença ou mesmo escárnio. Paradigmática desta atitude ambígua é sua apreciação não apenas estética da escritora George Sand, sobre quem escreve em Mon coeur mis à nus: "Não posso pensar nesta criatura estúpida sem um certo frêmito de horror". ${ }^{38}$ Ratificando seu juízo subalternizante, ele avalia que "Monsieur George" - como Nietzsche desdenhosamente se referia a ela era "uma destas velhas ingênuas que não querem nunca deixar as pranchas". ${ }^{39} \mathrm{Tal}$ contradição performativa não passa despercebida a Walter Benjamin, que observa: "Como Baudelaire não via a mulher lésbica como um problema - nem social nem de predisposição -, poderíamos dizer que também não tinha [...] nenhum posicionamento em relação a ela. Reservara-Ihe um espaço na imagem da Modernidade; na realidade não a reconhecia". ${ }^{40}$ Ressaltando a influência dos processos produtivos na irreversível modificação ou mesmo "masculinização" do corpo feminino à medida que mais e mais mulheres são assimiladas ao mundo do trabalho, Benjamin lança luzes sobre uma aproximação ainda pouco explorada entre os movimentos socialistas, o feminismo e a lesbianidade. Não obstante inferir a aprovação de Baudelaire em relação às mudanças em curso, o filósofo aponta uma grave inconsistência na postura do poeta ao incorporar o amor lésbico em seus escritos como pura excentricidade ou mera "fantasia" - de resto, perfeitamente conformada ao regime patriarcal e heteronormativo que lhe serve de lastro e inspiração.

Seria desacertado supor que tenha alguma vez ocorrido a Baudelaire intervir publicamente com seus poemas a favor da mulher lésbica. [...] O 'descei, descei, ó tristes vítimas' são as derradeiras palavras que o autor grita à mulher lésbica. Abandona-a à própria ruína. Não pode ser salva, porque a confusão em sua concepção baudelairiana é insolúvel. ${ }^{41}$

\section{O QUEER}

A despeito da precisão dos comentários benjaminianos, talvez, a título de epílogo, ainda seja factível defender, aqui, uma outra leitura. Pois se Baudelaire está longe de ser considerado, seja um autor feminista, seja um teórico do gênero, o protagonismo das lésbicas em As flores do mal poderia, extemporaneamente, ser tomado como um prenúncio - decerto tímido e vacilante - de algo que apenas mais de cem anos mais tarde seria chamado de "queer". Resultado da ressignificação da palavra inglesa utilizada originalmente em sentido pejorativo para se referir aos homossexuais como freaks, estranhos, desviantes, aberrantes ou até abjetos, o queer passaria a designar o 
movimento que, notadamente a partir dos anos 1990, levaria adiante as críticas e reivindicações dos estudos de gênero e LGBTs para além do registro da identidade, tomando como ponto de partida a necessidade de não mais tomar as mulheres como o sujeito único do feminismo. ${ }^{42}$ Neste sentido, a caracterização baudelairiana das heroínas lésbicas como porta-vozes da rejeição aos dispositivos que regulam a ordem médica, moral e legal de seu tempo encontra-se, de certo modo, alinhada aos princípios motrizes do queer como expediente genealógico de desconstrução dos binarismos - homemmulher, heterossexual-homossexual, normal-anormal - que estão na base do patriarcado e da heterossexualidade normativa como instituições fundantes da Modernidade ocidental. ${ }^{43}$ Ainda que poemas como "Mulheres malditas" e "Lesbos" se encerrem com um tom fortemente melancólico, resignado ou mesmo fatalista, a apresentação das lésbicas, ao mesmo tempo, como sensuais e puras, belas e horríveis, delinquentes $e$ injustiçadas, ou seja, como agentes de uma radical subversão dos sistemas morais, estéticos e jurídicos que as representam e as enquadram como "anormais", talvez isso possa ser tomado como fuga ou mesmo superação de um certo ordenamento naturalizado somente dentro do qual ficções sexuais como Delfina e Hipólita poderiam, rigorosamente, ser denominadas "mulheres".

Como explicará Monique Wittig já em 1980, a designação "mulher" faz parte de um persistente conglomerado de conceitos essenciais ou "primitivos" utilizados sem qualquer questionamento prévio. Forjados pelo que a autora se refere como "pensamento hétero" [straight mind] ${ }^{44}$, tais conceitos constituem os vestígios "naturais" que conseguiram escapar da démarche desconstrutivista levada a termo por pensadores pósestruturalistas como Lacan e Derrida.

\footnotetext{
Eles dizem respeito a 'mulher', 'homem', 'sexo', 'diferença', e a toda a série de conceitos que portam esta marca, incluindo conceitos como 'história', 'cultura' e 'real'. E embora tenha sido aceito em anos recentes que não existe semelhante coisa como natureza que tudo é cultura, permanece ainda um cerne de natureza que resiste a ser examinado, uma relação excluída na análise do social - uma relação cuja característica é inescapável na cultura, assim como na natureza, e que é a relação heterossexual, isto é, a relação social obrigatória entre 'homem' e 'mulher'.
}

Figura de proa para os estudos lésbicos e gays, e autora ainda muito pouco estudada no Brasil, Monique Wittig toca em uma questão que seria crucial também para Baudelaire, mesmo que em outro registro: a relação não problematizada entre o natural, o belo, o bom e o verdadeiro. Como vimos, o autor de As flores do mal apoia sua configuração poética das heroínas lésbicas em uma certa concepção estética - e, por derivação, também moral - que recusa sumariamente a natureza como fonte, modelo ou Ideal para qualquer criação ou conduta humana. Tanto que, em O pintor da vida moderna, o crítico busca desestabilizar um certo "primado da natureza" herdado do século XVIII, o qual postula que seus desvios devem ser eliminados pelos artistas, corrigidos pelos educadores, curados pelos médicos - e positivamente punidos pelo resto. Para Baudelaire, tal premissa é nada menos que a origem de todos os preconceitos e 
equívocos tomados como regra pelas autoridades de seu tempo. Donde o autor mobilizar a potência estética do mal como estratégia de transgressão ou "destruição" programática de seus fundamentos naturais. O resultado será a celebração da "beleza do horrível" encarnada em corpos insubmissos ou malditos - já que proscritos pela lei de Deus e dos homens. Segundo o poeta, as lésbicas são belas e "más" exatamente por atentarem contra a norma, descumprindo assim uma suposta vocação dada pela Natureza. Negando-se a desempenhar o papel de esposas e mães, les femmes damnées desdenham o trabalho reprodutivo e sexual compulsório prescrito pelo contrato matrimonial heterossexual. Deste modo, sem qualquer finalidade extrínseca, seu amor antinatural e também anormal - anseia tão somente pela consumação de um desejo "puro" e mesmo "desinteressado". Não visando a nada além de sua própria realização, corporifica, em plena carne, algo como uma versão pré-queer de "arte pela arte" ressignificada. Assim, lendo As flores do mal com Monique Wittig, talvez o inferno baudelairiano não seja, ao fim e ao cabo, uma punição ou um castigo terrível imposto pelo juízo final às amantes condenadas. Ao contrário, talvez represente, como queria Beauvoir, a derradeira libertação da biologia como destino da mulher. Afinal, nas palavras de Wittig:

O que é uma mulher? [...] Francamente, este é um problema que as lésbicas não têm devido a uma mudança de perspectiva, e seria incorreto dizer que as lésbicas se associam, fazem amor ou vivem com mulheres, pois 'mulher' tem um significado apenas em sistemas de pensamento e em sistemas econômicos heterossexuais. As lésbicas não são mulheres. ${ }^{46}$

Daí para Baudelaire seu caráter heroico.

\footnotetext{
* Alexia Bretas é professora do Departamento de Filosofia da UFABC.

*Uma versão reduzida desde artigo foi apresentada como comunicação oral no $13^{\circ}$ Congresso Internacional de Estética - Os fins da arte, na FAFICH-UFMG, em Belo Horizonte, em 19 de outubro de 2017.
}

${ }^{1}$ BENJAMIN, W. Passagens. Tradução do alemão de Irene Aron. Tradução do francês de Cleonice Paes Barreto Mourão. Belo Horizonte; São Paulo: Ed. UFMG; Imprensa Oficial do Estado de São Paulo, 2006, p. 361.

2 BAUDELAIRE, C. O pintor da vida moderna. Tradução de Tomaz Tadeu. Belo Horizonte: Autêntica, 2010, p. 17.

${ }^{3}$ Muito embora a chamada teoria queer tenha surgido apenas em fins do século $\mathrm{XX}$, acreditamos que valha a pena correr os riscos inerentes a nossa hipótese de trabalho, a qual leva adiante a tarefa de submeter duas das mais conhecidas obras de Baudelaire a um olhar histórico, crítico e desconstrutivo, em condições de situar seus escritos, extemporaneamente, dentro, mas também fora da matriz heteronormativa amparada pelos discursos médicos e jurídicos que ganham fôlego já em meados do século XIX - movimento que se encontra apenas esboçado na apreciação "estética" das mulheres em O pintor da vida moderna, bem como no protagonismo das personagens lésbicas, notadamente em As flores do mal. A título de esclarecimento, o termo queer foi utilizado pela primeira vez com o sentido que adotaremos neste artigo pela italiana Teresa de 
Lauretis - ainda que figuras como Judith Butler e Paul B. Preciado sejam constantemente citadas como importantes porta-vozes deste movimento autodeclarado pós-gay e pós-identitário. Nas palavras de Lauretis: "A expressão 'teoria queer' nasceu em 1990 como tema de um workshop que organizei na Universidade da Califórnia em Santa Cruz. O termo queer tem uma longa história; em inglês existe há mais de quatro séculos, e sempre com denotações e conotações negativas: estranho, excêntrico, vulgar, duvidoso ou questionável. Nos romances de Charles Dickens, Queer Street denominava uma parte de Londres em que viviam pessoas pobres, doentes e endividadas. No último século, após o famoso julgamento e o subsequente encarceramento de Oscar Wilde, a palavra queer foi associada principalmente à homossexualidade como um estigma. Foi o movimento de libertação gay dos anos 1970 que a fez uma palavra de orgulho e um sinal de resistência política. Como as palavras gay e lésbica, o queer designou, em primeiro lugar, um protesto social e, apenas em segundo lugar, uma identidade pessoal.

Meu projeto de 'teoria queer' consistia em iniciar um diálogo entre lésbicas e gays sobre sexualidade e sobre nossas respectivas histórias sexuais. Eu esperava que, juntos, quebrássemos os silêncios que haviam sido construídos nos 'Estudos lésbicos e gays' sobre a sexualidade e sua inter-relação com sexo e raça (por exemplo, o silêncio em torno de relações inter-raciais ou interétnicas). As duas palavras, teoria e queer, combinavam a crítica social e o trabalho conceitual e especulativo que envolve a produção do discurso. Eu contava com esse trabalho coletivo para construir outro horizonte discursivo, uma outra maneira de pensar sobre o sexual".

DE LAURETIS, T. “Gênero e teoria queer”. In: Mora, n. 21 (2015), p. 109 (nossa tradução).

${ }^{4}$ Sobre a necessidade de enunciar a pergunta "O que é uma mulher" desde um ponto de vista não masculinista, ver BEAUVOIR, S. O segundo sexo. Tradução de Sérgio Millet. Rio de Janeiro: Nova Fronteira, 2009, pp. 13-31; e CYFER, I. "Afinal, o que é uma mulher? Simone de Beauvoir e a 'questão do sujeito' na teoria crítica feminista”. In: Lua Nova, n. 94 (2015), pp. 41-77.

${ }^{5}$ BAUDELAIRE, C. O pintor da vida moderna. Op. cit., p. 67.

${ }^{6}$ Sobre os múltiplos processos de subalternização e silenciamento da mulher - e, especialmente, da mulher negra e/ou do Sul global - como sujeito de entendimento, linguagem e ação, cf. SPIVAK, G. C. Pode o subalterno falar? Tradução de Sandra Regina Goulart Almeida. Belo Horizonte: Ed. UFMG, 2010; e KILOMBA, G. Plantation Memories: Episodes of Everyday Racism. Münster: Unrast, 2016.

7 Ver KRAFFT-EBING, R. Psychopathia sexualis. Tradução de Franklin S. Klaf. New York: Skyhorse, 2011; e FOUCAULT, M. A história da sexualidade I: A vontade de saber. Tradução de Maria Thereza da Costa Albuquerque e J. A. Guilhon Albuquerque. Rio de Janeiro: Graal, 1988, pp. 9-19.

${ }^{8}$ NIETZSCHE, F. Além do bem e do mal: prelúdio a uma filosofia do futuro. Tradução de Paulo César de Souza. São Paulo: Companhia das Letras, 1992, p. 145.

${ }^{9}$ Idem. Humano, demasiado humano: um livro para espíritos livres. Tradução de Paulo César de Souza. São Paulo: Companhia das Letras, 2000, p. 140.

${ }^{10}$ Ibidem, p. 140.

${ }^{11}$ SCHOPENHAUER, A. A arte de lidar com as mulheres. Tradução de Eurides Avance de Souza e Karina Jannini. São Paulo: Martins Fontes, 2011, p. 6.

12 Ibidem, p. 7.

${ }^{13}$ Ibidem, p. 4.

${ }^{14}$ Ver BEAUVOIR, S. O segundo sexo. Op. cit., pp. 35-95.

${ }^{15}$ SCHOPENHAUER, A. Op. cit., p. 14. 
${ }^{16}$ Em sua réplica a Rousseau, quando diz que, em relação ao caráter feminino, a obediência é a única grande lição a ser inculcada com todo o rigor, Wollstonecraft, ainda em 1791, afirma: "Que bobagem! Quando surgirá um homem com força mental suficiente para dissipar a névoa que o orgulho e a sensualidade têm espalhado sobre o assunto?" WOLLSTONECRAFT, M. Reivindicação dos direitos da mulher. Tradução de Ivania Pocinho Motta. São Paulo: Boitempo, 2016, p. 47.

${ }^{17}$ Ver NOCHLIN, L. Por que não houve grandes mulheres artistas? Tradução de Juliana Vacaro. São Paulo: Ed. Aurora, 2016; e CHADWICK, W. Women, Art, and Society. Londres: Thames \& Hudson, 2012.

${ }^{18}$ SCHOPENHAUER, A. Op. cit., p. 67.

${ }^{19}$ BAUDELAIRE, C. O pintor da vida moderna. Op. cit., p. 69.

20 Ibidem, p. 71.

${ }^{21}$ BAUDELAIRE, C. O pintor da vida moderna. Op. cit., p. 72.

22 Ibidem, p. 73.

${ }^{23}$ Ibidem, p. 81.

${ }^{24}$ Ibidem.

${ }^{25}$ Idem. As flores do mal. Tradução de Ivo Junqueira. Rio de Janeiro: Nova Fronteira, 1985, p. 66.

${ }^{26}$ Ibidem, p. 66.

${ }^{27}$ BAUDELAIRE, C. As flores do mal. Op. cit., p. 398.

${ }^{28}$ Paul Beatriz Preciado relembra suas impressões sobre a primeira vez que foi a Lesbos, nos idos dos anos 90, a fim de consumar o que chama de "verdadeiro processo de iniciação políticosexual". "A primeira imagem da praia de Eressos permanece intacta na minha memória como um hino à utopia, como um chamado à revolução. Era o impossível tornado realidade: um quilômetro de areia e de mar ocupado por quinhentas lésbicas nuas". Paraíso da radicalidade lésbica na década de 90, a ilha, no entanto, é hoje um entreposto marcado pelos assentamentos militares e pelo grande afluxo de migrantes vindos da Turquia e da África. Nas palavras de Preciado, "Lesbos se tornou a Tijuana da Europa". PRECIADO, P. B. "Voyage a Lesbos". Disponível em: <http://www.liberation.fr/debats/2016/07/26/voyage-a-lesbos_1468660>. Acesso em: 9/9/2017 (nossa tradução).

${ }^{29}$ Anne Carson chama atenção para o fato de ter sido Safo a primeira a caracterizar Eros como o deus "agridoce" (bittersweet). Ver CARSON, A. Eros the Bittersweet. McLean: Dalkey Archive Press, 1998.

${ }^{30}$ No clássico de Richard Krafft-Ebing, Psychopathia Sexualis (1886), o "amor lésbico" aparece enquadrado como "patologia". Segundo Coffignon, esta prática encontra-se "na moda", devido em parte aos romances sobre o tema, em parte às novas configurações das relações de trabalho. $O$ autor declara que estas "amizades proibidas", diagnosticadas e patologizadas como "safismo", tendem a florescer especialmente em instituições penais para mulheres, além de serem mais frequentes entre aristocratas e prostitutas - entre si, chamadas de "irmãzinhas". KRAFFT-EBING. Psychopathia Sexualis. Op. cit., pp. 758-764.

${ }^{31}$ BENJAMIN, W. Obras escolhidas III. Charles Baudelaire, um lírico no auge do capitalismo. Tradução de José Carlos Martins Barbosa e Hemerson Alves Baptista. São Paulo: Perspectiva, 1994, p. 88.

${ }^{32}$ MATOS, O. "Um surrealism platônico". In: NOVAES, A. (org). Poetas que pensaram o mundo. São Paulo: Companhia das Letras, 2005, p. 319.

${ }^{33}$ BAUDELAIRE, C. As flores do mal. Op. cit., p. 500. 
${ }^{34}$ Ibidem, p. 500.

${ }^{35}$ Ibidem, p. 508.

${ }^{36}$ Ibidem.

${ }^{37}$ KRAFFT-EBING, R. Psychopathia sexualis. Op. cit., p. 37 (nossa tradução).

${ }^{38}$ BAUDELAIRE, C. As flores do mal. Op. cit., p. 51.

39 Ibidem, p. 51.

${ }^{40}$ BENJAMIN, W. Obras escolhidas III. Op. cit., pp. 90-91.

${ }^{41}$ Ibidem, p. 91.

${ }^{42}$ Ver BUTLER, J. Problemas de gênero: feminismo e subversão da identidade. Tradução de: Renato Aguiar. Rio de Janeiro: Civilização Brasileira, 2016, pp. 17-25.

43 'Quando se fala de teoria 'queer' para se referir aos textos de Judith Butler, Teresa de Lauretis, Eve K. Sedgwick ou Michael Warner, fala-se de um projeto crítico herdeiro da tradição feminista e anticolonial, que tem por objetivo a análise e a desconstrução dos processos históricos e culturais que nos conduziram à invenção do corpo branco heterossexual como ficção dominante no Ocidente, e à exclusão das diferenças para fora do âmbito da representação política". PRECIADO, P. B. "Queer, historia de una palabra". Disponível em: <http://paroledequeer.blogspot.com.br/2012/04/queer-historia-de-una-palabra-por.html>. Acesso em: 4/10/2017 (nossa tradução).

${ }^{44}$ A expressão "straight mind" foi cunhada nos anos 1980 por Monique Wittig com base em sua leitura crítica de O pensamento selvagem (The Savage Mind) de Claude Lévi-Strauss.

${ }^{45}$ WITTIG, M. The Straight Mind and Other Essays. Boston: Beacon, 1992, p. 27 (nossa tradução).

${ }^{46}$ Ibidem, p. 32 (nossa tradução). 